\title{
Southern African Coloured
}

National Cancer Institute

\section{Source}

National Cancer Institute. Southern African Coloured. NCI Thesaurus. Code C156583.

A person of mixed race, whose ancestry is from one or more of the naturalized racial groups of Southern Africa (typically Western European, South Asian, or Southeastern Asian) and one or more of the indigenous Southern African peoples. 